Check for updates

The BMJ

Cite this as: BMJ 2021;372:n480 http://dx.doi.org/10.1136/bmi.n480 Published: 18 February 2021

\section{Flu vaccination: Lansley reforms caused London to fall behind in uptake, report finds}

Gareth lacobucci

The Health and Social Care Act 2012 led to London falling behind in flu vaccination rates, a report has concluded.

The centralisation of vaccine coordination that stemmed from Andrew Lansley's reforms disproportionately affected London, said the report from the Royal Society for Public Health. ${ }^{1}$

The reforms led to just one person being accountable for flu vaccination across the whole of London, covering 2.2 million eligible patients and 2186 general practices. After the 2012 act the ratio of patients to each individual immunisation lead increased by 36 times in London, compared with seven times in the South West and North West regions.

The report also noted that, since the act came in, the gap between overall flu vaccination rates around England and the rates in London grew from $1.8 \%$ to $6.2 \%$ (2011 to 2019-20). Recent figures show that under two thirds of people over 65 receive the flu vaccination in London, compared with $74 \%$ in Greater Manchester.

Previous good progress made from 2004 to 2011 in London - when coverage increased from 67.5\% to $72.2 \%$-has now reversed, the report added. It highlighted that, even in this winter when flu vaccination rates have increased, London still lags behind with an uptake of $70.6 \%$, while all other regions have exceeded the $75 \%$ target set by the World Health Organization.

One notable exception in London was Tower Hamlets, which was by far the highest performing borough for uptake among all groups. The report attributed this to the area being the first to develop primary care networks, which fostered greater system level coordination and helped to boost rates.

\section{Closer to communities}

The report called for a review to determine where strategic responsibility for improving immunisation coverage sits and for the commissioning of vaccination services to be made more local. NHS England and Improvement should also set up local immunisation coordinator roles, to drive coordination and uptake between different providers such as GPs and pharmacists, it advised.

Christina Marriott, chief executive of the Royal Society for Public Health, said, "With high levels of deprivation and ethnic diversity, London is home to many groups that are time and again let down by our health system. But the story of boroughs like Tower Hamlets, with the highest uptake rates in one of the most deprived populations in the capital, tell us things need not be this way.

"To end this cycle, the coordination and commissioning of vaccination need to be brought closer to the communities they serve, and we hope this report sets out a path to doing so.”

Doug Brown, chief executive of the British Society for Immunology, said, "We support the recommendation for NHS England and NHS Improvement to establish the local immunisation coordinator roles to act as 'on the ground' champions for vaccination. This, coupled with increased accessibility of services, community outreach, and funding, will ensure we have a strong vaccination framework beyond the pandemic.”

Royal Society for Public Health. Mind the Gap: London's low flu vaccination rates and how to fix them. Feb 2021. https://www.rsph.org.uk/our-work/policy/vaccinations/mind-the-gap.html. 